\title{
Perfil del usuario y propuesta de zonificación para el manejo de visitantes: el caso de la reserva privada Juanilama, Costa Rica
}

\author{
July Guerrero, Bach. ${ }^{1}$ \& Adrián Ruiz Rodríguez, M. Sc. ${ }^{2}$ \\ 1. jus0003@hotmail.es \\ 2.Profesor UNED; aruiz@uned.ac.cr
}

Recibido: 06 mayo 2016

\section{RESUMEN}

Se investigaron las prioridades de manejo de la reserva en cuanto al perfil y gestión de visitantes, las zonas de uso público y las problemáticas presentes por la ausencia de unidades de zonificación. Se obtuvo que el visitante es predominantemente extranjero, joven estudiante y que visita la Reserva por primera vez. Por la vulnerabilidad de los ecosistemas y sus recursos, así como por las prioridades de uso del sitio de la administración, se establecieron cuatro zonas en la propuesta de zonificación: Zona Restringida; Zona de Uso Extensivo, Zona de Uso Intensivo y la Zona de Uso Especial. Se recomienda la aplicación de normas y políticas para el manejo de visitantes con el fin de proteger la dinámica natural de los ecosistemas.

Palabras clave: visitantes, zonificación, manejo de visitantes, Reserva Juanilama.

\begin{abstract}
Management priorities related to visitors and tourists in the public zone of Juanilama Reserve was the main targets of this research. Visitors profile, public regulations and land use categories had the study focus, through no probabilistic survey methods. The visitors' profile recognized a bigger percentage of foreign users, young and adults, who were looking for touristic and vacation destinations in the area. It was established some actions for the reserve management. For the land use and area regulation, four main spaces where proposed: restricted area, intensive use area, extensive use spaces and special area. For the land zones and visitors management plans, is important to implement norms and political proposals included, in order to protect natural resources and ecosystems' cycles in Juanilama.
\end{abstract}

Key words: visitors, land use categories, visitors management, Juanilama reserve.
Aceptado: 17 mayo 2016

\section{Introducción}

La reserva Juanilama es un área rica en biodiversidad. Su territorio de aproximadamente 19 hectáreas, se ha destinado a la protección y conservación de flora y fauna. Es criterio de su administrador que posee importancia hídrica y vocación forestal (Calvo, comunicación personal 2013).

En años recientes le incremento de llegadas de visitantes generó interés y necesidad de establecer propuestas para mejorar la gestión del espacio y de los visitantes, con el fin de prevenir y mitigar impactos ambientales, así como empezar a proyectar la reserva como espacio de conservación, educación, recreación y desarrollo local.

\section{Zonas de Uso Público (ZUP)}

Es "un espacio físico del área protegida reservada a los visitantes para que realicen sus actividades de recreación y aprendizaje acerca de los atractivos naturales y culturales presentes en el área protegida..." (Bermúdez, 2007). Aunque se han creado distintas definiciones de uso público por parte de organismos gestores se mantienen ciertos criterios comunes que le son esenciales, como por ejemplo, el acercamiento a los valores de los recursos, la contribución a la conservación, la necesidad de que los usos y actividades estén ordenados y el carácter educativo de su práctica (Hernández y Gómez-Limón, 2005). 


\section{Manejo de visitantes}

El manejo de visitantes constituye un conjunto de políticas, directrices, instrumentos, y/o actividades que establece la administración de un Área Silvestre Protegida (ASP) para facilitar al visitante el disfrute de los recursos naturales y culturales, sin que se comprometa la integridad de los recursos (Bermúdez, 2007).

\section{Sistema de Manejo de Visitantes (SIMAVIS)}

El Sistema de Manejo de Visitantes (SIMAVIS), es una metodología de planificación que propone un manejo adecuado de las oportunidades de uso público en áreas protegidas y otros espacios turísticos, en base de criterios de calidad de la experiencia de los visitantes, respetando siempre los objetivos de conservación. Esta metodología se adapta a las condiciones de cada área, tomando en cuenta aspectos naturales y físico-geográficos, como también sociales, culturales y de intervención humana.

SIMAVIS, se basa en una serie de principios y pasos:

- Los impactos de los visitantes no son proporcionales a su número, sino principalmente a su comportamiento.

- En lugar de determinar una capacidad de carga, se determina una serie de características naturales (calidad del entorno y de la biodiversidad), sociales (densidad de visitantes e interacción entre ellos) y de manejo (señalización, equipamiento), que deben ser mantenidas dentro de límites establecidos. El uso produce cambios o impactos que no deben sobrepasar umbrales (límites) determinados como aceptables.

- Un esquema de zonificación de las áreas de uso turístico procura la satisfacción de diferentes expectativas de visitantes a la vez del mantenimiento de diferentes escenarios de naturalidad y conservación en los sitios.

- Se enfocan fuertemente en la calidad de la experiencia de los visitantes, por tanto valora mucho el análisis y las percepciones subjetivas y empíricas de los actores sociales.
- La metodología tiene como pilar fundamental la participación activa de los actores relacionados en los procesos turísticos de las áreas protegidas (desde el sector público y privado).

\section{Zonificación}

Para el cumplimiento de los objetivos de conservación de un área protegida, se permiten los usos tanto directos como indirectos y estos deben ser ubicados y ordenados espacialmente.

Artavia (2004) citado por Bermúdez (2007), indica que la definición de zonas de manejo es: "La organización del territorio de un área silvestre protegida en función del valor de sus recursos y de su capacidad de acogida para los distintos usos, en la que se establecen objetivos muy claros y precisos y con la normativa correspondiente, con el fin de minimizar los impactos negativos y de asegurar un uso del espacio compatible con la conservación de los recursos naturales y culturales presentes en el área y su relación con la dinámica socio ambiental de su entorno inmediato"

\section{Metodología}

\section{Ubicación}

La Reserva Juanilama está localizada en Pocosol de San Carlos, Alajuela. Esta reserva pertenece a la hoja cartográfica de Monterrey 061 (Instituto Geográfico Nacional), la cual está ubicada entre las coordenadas $\mathrm{N} 10^{\circ} 39.628^{\prime}$ y W $084^{\circ} 33.888^{\prime}$. (Fig. 1)

\section{Tipo y diseño de investigación}

Para este proyecto el tipo de estudio tuvo un enfoque mixto, el cual implica la recolección y el análisis de datos cuantitativos y cualitativos, así como su integración y discusión conjunta, para realizar inferencias producto de toda la información recabada y lograr un mayor entendimiento del fenómeno bajo estudio.

Las preguntas de investigación precedieron a la recolección y análisis de los datos, con cuestiones abiertas a la población objeto de 


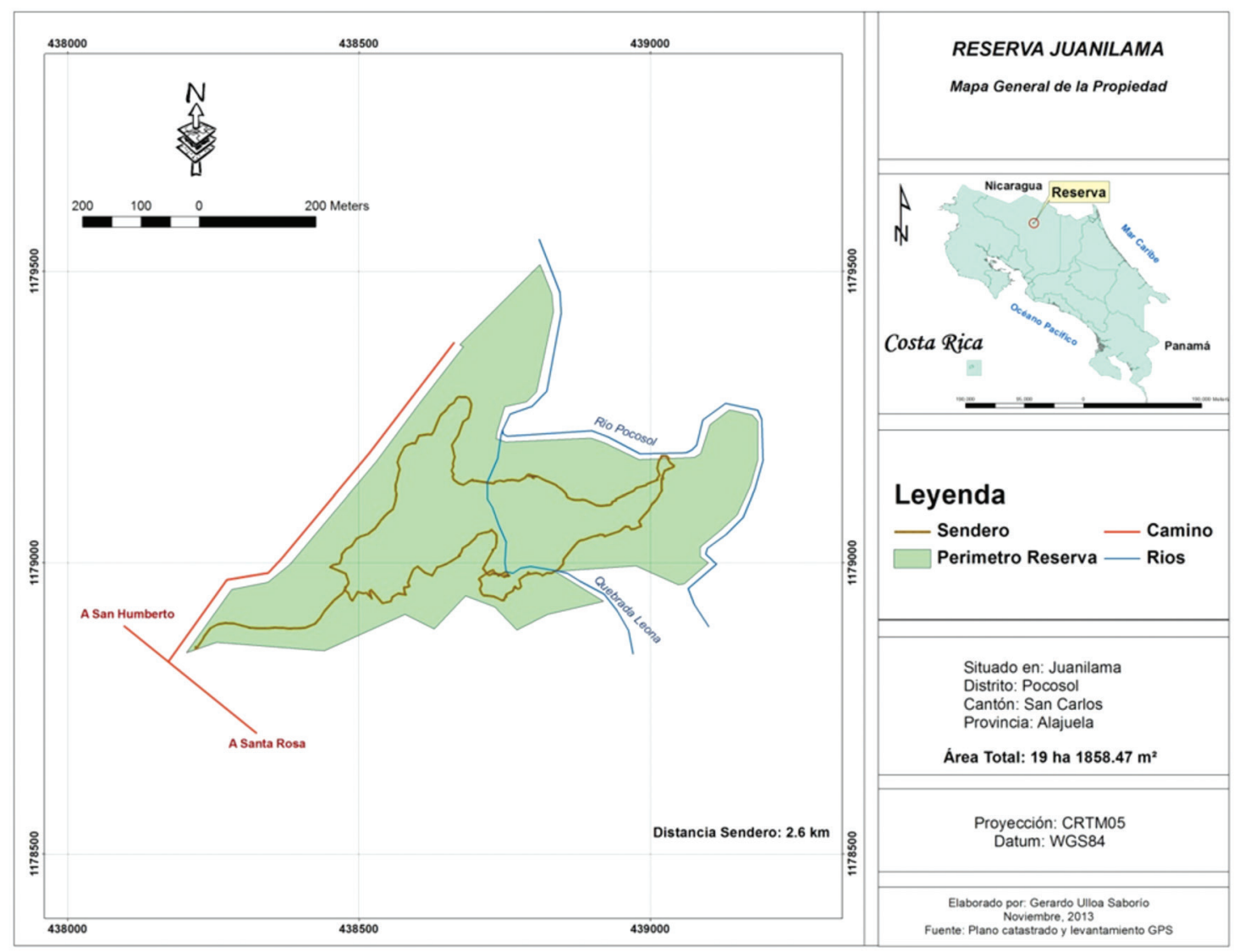

Figura 1. Mapa de ubicación de Reserva Juanilama. Fuente: Ulloa, 2013.

estudio mediante entrevistas abiertas o semiestructuradas programadas durante las visitas al sitio, con el fin de obtener datos cualitativos respecto a interacciones, conductas observadas y sus manifestaciones.

\section{Población objeto de estudio}

Se identificaron dos tipos de informantes a los que se dirige la investigación, el personal administrativo de la reserva Juanilama y los visitantes de la reserva tanto nacionales como extranjeros. El primer informante al que se contribuye con la propuesta de manejo de visitantes es el personal administrativo del área en estudio, los cuales no cuentan con un plan de manejo, por lo que se les beneficia con la propuesta base de este trabajo.

El segundo informante fueron las personas tanto extranjeras como nacionales que ingresan a la reserva Juanilama, a quienes se les pretendió mejorar el uso e interacción de los ecosistemas.

\section{Criterios de las unidades de estudio}

Las personas involucradas en la investigación fueron residentes cercanos al área de estudio con varios años de vivir en la zona, esto con el fin de obtener datos más precisos sobre la evolución en el desarrollo turístico de la reserva. Fueron clave también los visitantes temporales nacionales o extranjeros con intereses en los recursos naturales o históricos culturales.

\section{Zonificación de sitios}

La zonificación constituye una parte fundamental al establecer medidas para cada espacio geográfico con el objeto de prevenir, controlar, mitigar, corregir y, en su caso, revertir 
desequilibrios ocasionados por las actividades humanas no sustentables. Para esta etapa se determinó el perfil de los visitantes, necesidades e intereses de manejo de los mismos por parte del personal de la Reserva.

Fue elemental el uso de Sistemas de Información Geográfica, encuestas a usuarios actuales y/o potenciales, evaluaciones ecológicas, entre otras para determinar las diferentes zonas de acuerdo con los objetivos del área y sus condiciones ecológicas. Se estableció la clasificación de zonas, su ubicación, longitud y se establecieron restricciones de uso y manejo, para definir los usos permisibles y deseables, para los que se establecieron propuestas de lineamientos para la gestión de usuarios.

Se utilizó el cuadro 1 de caracterización para determinar las zonas propuestas.

\section{Resultados}

\section{Administración y personal}

de la Reserva Juanilama

La administración de la Reserva Juanilama está a cargo de la Asociación Agroecológica Juanilama, que en conjunto la Junta Directiva y seis familias de la comunidad.

Por falta de fondos no se cuenta con personal suficiente para una mejor planeación, organización, dirección y control de la reserva. Hay escasez de personal para guías y vigilantes; por lo que las mismas personas de la Asociación han asumido el cargo de recepcionistas y guías locales.

La Asociación Agroecológica Juanilama en su lucha por promocionarse en el turismo

\section{CUADRO 1}

\section{Aspectos para determinar la zonificación}

\begin{tabular}{|c|c|c|c|c|}
\hline \multirow[b]{2}{*}{ Zona (color) } & \multirow[b]{2}{*}{ Características } & \multicolumn{2}{|c|}{ Valor } & \multirow{2}{*}{$\begin{array}{l}\text { Usos } \\
\text { permitidos (P), } \\
\text { regulados (R) y } \\
\text { potenciales (Pt) }\end{array}$} \\
\hline & & Ambiental & $\begin{array}{c}\text { Patrimonial, } \\
\text { histórico, cultural }\end{array}$ & \\
\hline $\begin{array}{l}\text { Restringida } \\
\text { (Rojo) }\end{array}$ & $\begin{array}{l}\text { Sectores con elevado grado de naturalidad. } \\
\text { Aunque hayan podido sufrir un cierto grado de } \\
\text { intervención humana, mantienen sus valores } \\
\text { naturales en buen estado o se encuentran en } \\
\text { proceso de regeneración. Se puede desarrollar } \\
\text { uso público o turismo especializado en forma } \\
\text { esporádica, con autorización y control de la ad- } \\
\text { ministración del área. Condiciones de acceso y } \\
\text { recorrido con un grado de dificultad alto. }\end{array}$ & Muy alto & Bajo & \\
\hline $\begin{array}{l}\text { Uso público } \\
\text { (extensiva) (naranja) }\end{array}$ & $\begin{array}{l}\text { Sitios naturales con grandes atractivos paisajís- } \\
\text { ticos, presenta un grado de fragilidad física o } \\
\text { biológica. Entorno con escaza o ninguna alte- } \\
\text { ración antropogénica, bosques en estado de } \\
\text { sucesión y excelente estado de conservación. }\end{array}$ & Alto & Medio & \\
\hline $\begin{array}{l}\text { Uso público } \\
\text { (Intensiva) (Amarillo) }\end{array}$ & $\begin{array}{l}\text { Entorno natural con buen estado de conserva- } \\
\text { ción, con especies introducidas escazas. Zona } \\
\text { conectada con el área de ingreso principal. }\end{array}$ & Medio & Bajo & \\
\hline $\begin{array}{l}\text { Zona de uso especial } \\
\text { (verde) }\end{array}$ & $\begin{array}{l}\text { Sitios modificados especialmente para el uso } \\
\text { público dentro de un paisaje natural o semi na- } \\
\text { tural. Con infraestructura adaptaba para la en- } \\
\text { señanza ambiental. Alta capacidad de soporte, } \\
\text { facilidades y servicios guardando siempre las } \\
\text { consideraciones ambientales. }\end{array}$ & Bajo & Alto & \\
\hline
\end{tabular}

Fuente: Elaboración propia a partir de Ruíz, A. (2015) y Gunter, R. (2011). 
ecológico ha buscado métodos como la invitación de agencias de turismo para exponer sus propuestas esto con el fin de conseguir vínculos y contactos para atraer visitantes. Mediante este sistema han venido fortaleciéndose en los últimos años gracias al interés de las agencias de viajes en las propuestas de turismo rural y ecoturismo.

En la actualidad han establecido contratos por periodos de entre uno y dos años con las agencias que están trabajando hasta la fecha, estas agencias son Ecotours, Puraventura, Intrepid, Aventuras Bajo el Sol, Actuar y Boyero Tours Costa Rica (Molina, comunicación personal, 2016).

\section{Perfil del visitante}

La visitación anual en promedio a la reserva Juanilama, de acuerdo a los datos de los últimos cinco años, es de 183 personas; sin embargo, se debe señalar que solo en los últimos dos años (2013-2015) se registró un aumento significativo de visitas, ya que, en ese periodo a la fecha de Junio, se registró en total una asistencia de 822 personas al sitio; lo que podría influir en no generar un dato más preciso a la hora de determinar un promedio anual, basado en los últimos cinco años (Salazar, comunicación personal, 2015).

El perfil del visitante generalmente es el de voluntariado extranjero principalmente Estadounidense; jóvenes entre los 11 a 16 años, los cuales conforman grupos de 15-20 personas aproximadamente, estos asumen su interés en la ayuda comunitaria y del ambiente.

Además a menor escala se atienden visitantes extranjeros de avanzada edad, provenientes de diversos países de Latinoamérica, Estados Unidos y de Europa; que se ven limitados al ingreso del sitio en estudio por falta de sistemas de seguridad para este perfil de visitante dentro de la reserva. Este tipo de visitantes buscan en su mayoría la recreación, apreciación del paisaje y el descanso.

Además en menor proporción están los visitantes nacionales, principalmente estudiantes de diversas universidades del país, que llegan con la intensión de realizar investigaciones de varios índoles en el área de las ciencias naturales y las personas que viven cerca de la zona, principalmente adolescentes que ingresan con motivo de recreación a la Catarata La Leona.

De modo complementario a la información brindada por los funcionarios de la reserva, se obtuvo el siguiente perfil del visitante partiendo del trabajo de campo y aplicación de cuestionarios.

\section{Información Personal}

Según los resultados de las encuestas aplicadas, la edad de los visitantes tanto nacionales como extranjeros oscila entre los 26-79 años. Además estos provenientes en su mayoría del continente Europeo, países como Alemania, Inglaterra, Suecia, Escocia y España; sin embargo, se registraron visitas del continente Americano provenientes de países como Canadá y Estados Unidos. En el mínimo de los casos se registraron ingresos de visitantes procedentes de Australia.

Este tipo de visitante extranjero organizó su visita con agencia de viaje u operador turístico, el cual les brinda el servicio de transporte y los paquetes del plan turístico. (Fig. 2, Fig. 3, Fig. 4)

La mayoría de los visitantes coincidieron en que el motivo de sus visitas a la reserva fue por causa de turismo/vacaciones. Mientras que solo el $20 \%$ indicó que fue por otros motivos que abarcan motivos laborales o como un medio de

\section{Sexo}

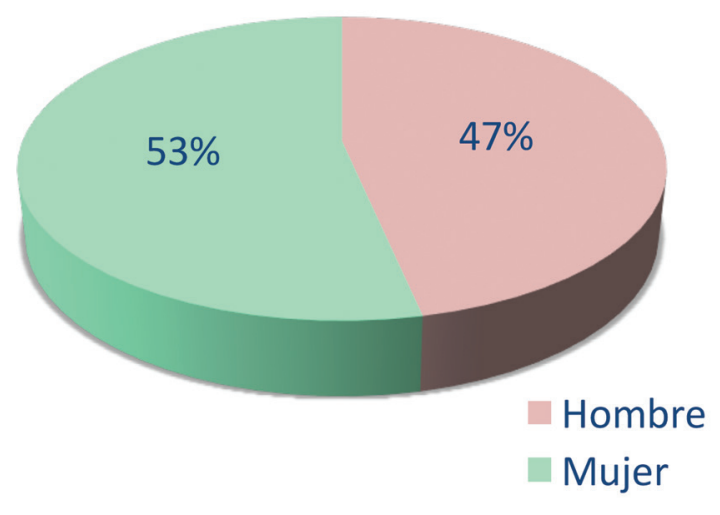

Figura 2. Distribución por sexos de los entrevistados. Fuente: entrevista a los informantes, 2015. 


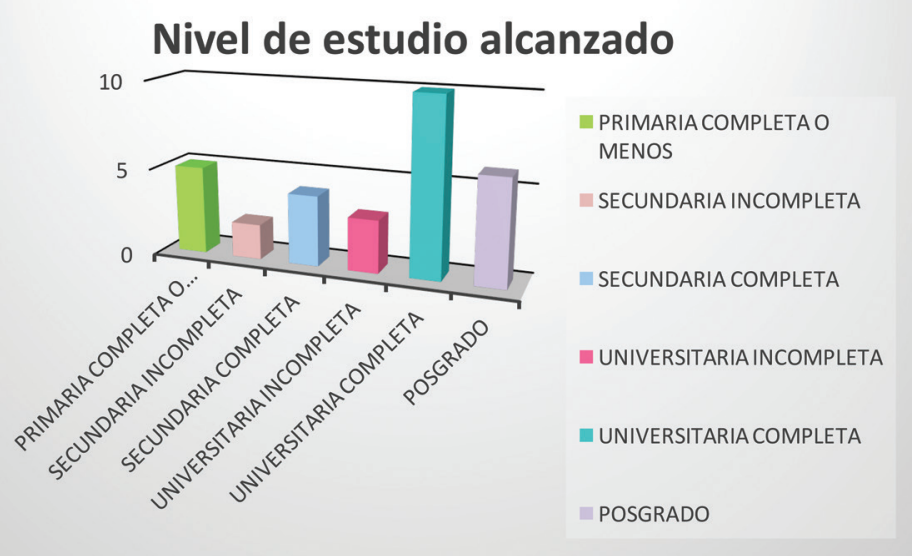

Figura 3. Nivel de estudios alcanzado por los entrevistados. Fuente: entrevista a los informantes, 2015.

\section{MOTIVO DE LA VISITA}

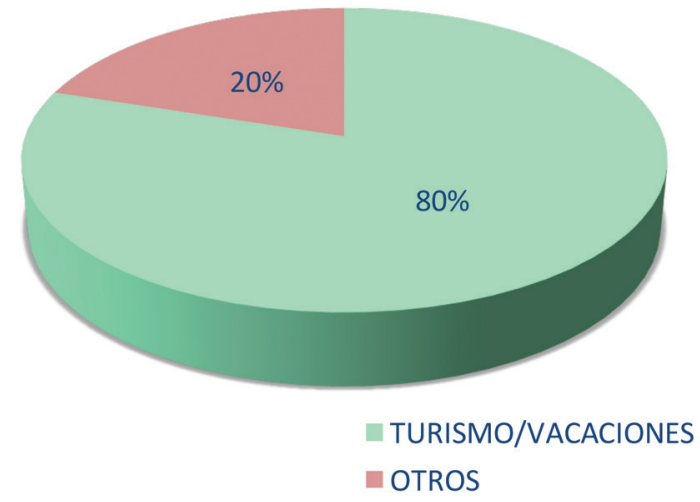

Figura 4. Distribución por motivo que infirió en la visita a la reserva Juanilama. Fuente: entrevista a los informantes, 2015. recreación temporal; este $20 \%$ abarca principalmente a los visitantes nacionales. (Fig. 5)

Se logró identificar que la mayoría de personas que ingresaron a la reserva organizaron su visita a partir de un paquete turístico. Estos casos son de visitantes extranjeros que recurren a este servicio directamente por medio de una agencia de viajes u operador turístico. En menor cantidad se obtuvo que otros organizaban sus visitas con grupos de amigos o la familia. (Cuadro 2)

La tabla anterior muestra, que los principales medios de información sobre los cuales se dan por enterados de la existencia de la Reserva Juanilama los informantes, fueron por medio de agencia de viajes u operador turístico en su

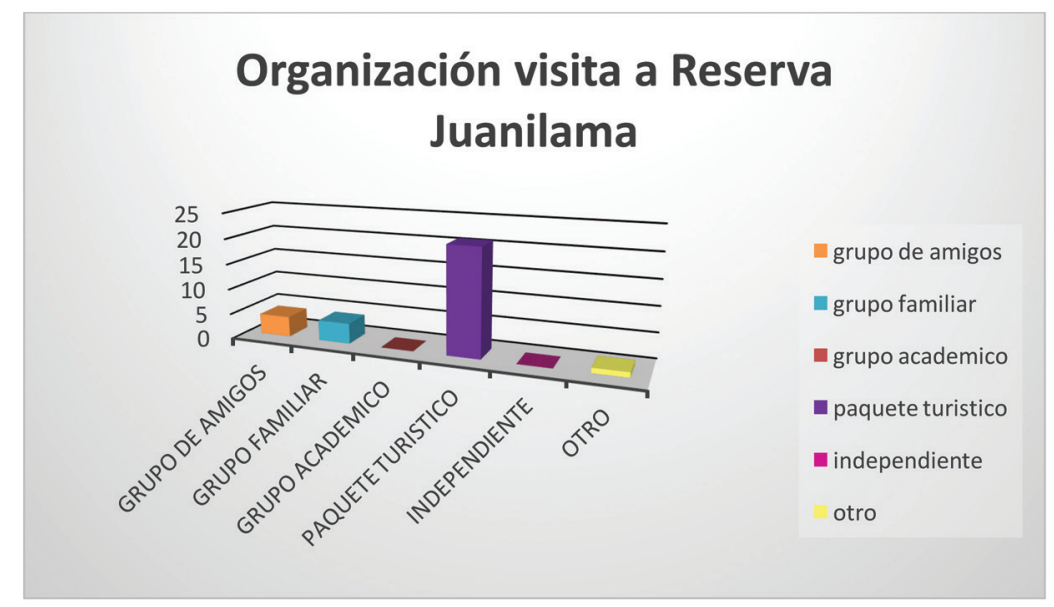

Figura 5. Distribución por medio comunicativo con el cual se organizó la visita a la Reserva Juanilama. Fuente: entrevista a los informantes, 2015. 
CUADRo 2

\section{Medios de información utilizados al enterarse de la existencia de la reserva Juanilama.}

\section{Principal medio de información sobre existencia} de la reserva Juanilama

\begin{tabular}{lc} 
Amigos/Familia & 8 \\
Revista/Periódico & 0 \\
\hline Televisión & 0 \\
Guías de turismo & 9 \\
Agencia de viajes/Operador de Turismo & 13 \\
Internet & 0 \\
Otros & 0
\end{tabular}

Fuente: entrevista a los informantes, 2015.

mayoría, y en cantidades muy semejantes se registró que por medio de guías de turismo y como parte de comunicación personal entre familiares y amigos. Esto refleja lo indicado por el personal de la reserva al mencionar que trabajan por medio de convenios con agencias de turismo $\mathrm{u}$ operadores de turismo. (Fig. 6)

El principal medio de transporte utilizado para ingresar a la reserva Juanilama es por medio de bus de turismo; esto en relación con los datos del gráfico de la Figura 6, donde se muestra que los operadores o agencias de turismo trabajan con paquetes que incluyen ese servicio. Las otras formas registradas de ingreso a la reserva fue un en vehículo propio (moto o caballo), y el otro número significativo es el de visitante nacional de la zona que lo hizo caminando desde sus hogares hasta el sitio; al encontrarse cerca de la zona. Esto se muestra como "otro" en el gráfico anterior (Fig. 6).

El gráfico anterior (Fig. 7) muestra un dato contundente, en el cual se aprecia que el $77 \%$ de los encuestados respondió que aparte de esa vez, nunca antes habían visitado la Reserva Juanilama, en el caso de extranjeros por la distancia y la dificultad para visitar el área regularmente. En segundo lugar con un 13\% otros encuestados indicaron muy al contrario, haber ingresado más de tres veces; este es el caso de visitantes nacionales, esto debido a su cercanía a la zona.

El porcentaje restante corresponde a vecinos de la zona que no se sienten muy atraídos hacia la reserva, ya que les resulta muy común el ecosistema y lo que ahí habita.

El gráfico anterior (Fig. 8) muestra que la mayoría de visitantes permanece más de 5 horas en la Reserva; sin embargo, este tiempo se distribuye en varias actividades desde caminatas en el interior de la reserva como la estancia en la zona de uso especial donde desarrollan otras actividades como talleres de manualidades, confección de artículos a partir de productos naturales o de reciclaje, entre otros.

El 53\% de los encuestados indicaron no interesarse por un atractivo en especial, la mayoría indicaron como atractivo todas las opciones

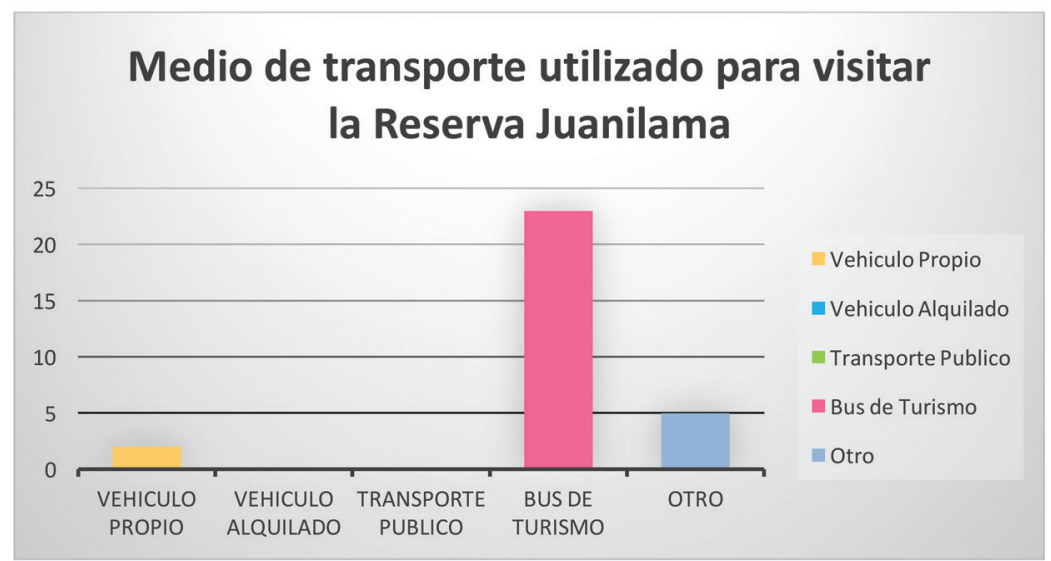

Figura 6. Distribución de las visitas de acuerdo al medio de transporte utilizado para llegar a la reserva Juanilama. Fuente: entrevista a los informantes, 2015. 


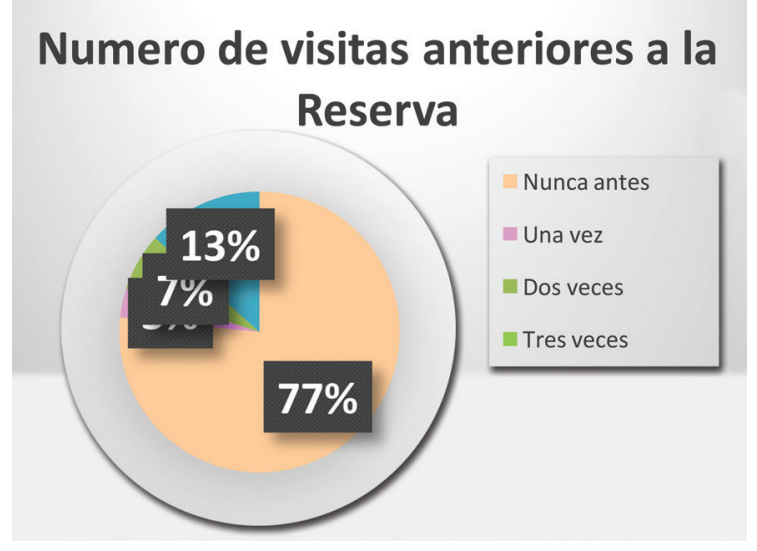

Figura 7. Porcentaje de visitas realizadas por los visitantes anteriormente al día de aplicación de la encuesta. Fuente: entrevista a los informantes, 2015.

anteriores, es decir, la flora, fauna y el ecosistema (Fig. 9). Además de esto gran cantidad mencionó el interés por la cultura y la gente de la zona, sus formas de vida, entre otros. En segundo lugar un $30 \%$ de los encuestados mostraron su interés por el ecosistema del área en estudio. Indicaron fascinación al presenciar un ecosistema en el cual no estaban acostumbrados a ver, ni vivir.

Los datos obtenidos de las encuestas aplicadas a los visitantes, permite tener una visión sobre lo que se debe presentar como una Propuesta de Manejo de Visitantes, siendo este factor

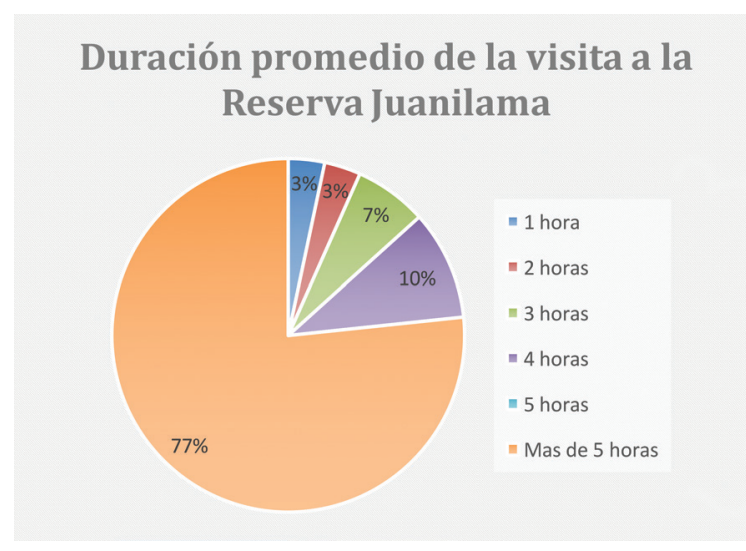

Figura 8. Duración promedio de las visitas a la Reserva Juanilama. Fuente: entrevista a los informantes, 2015.

importante en la toma de decisiones por parte de la administración de la reserva Juanilama en cuanto al desarrollo del turismo ecológico. Por lo tanto los datos anteriores permiten considerar una propuesta sobre manejo de visitantes más eficaz analizando además las zonas de uso público.

\section{Propuesta de zonificación}

Por medio de la zonificación del interior de la Reserva Juanilama, se busca establecer áreas territoriales que merezcan un tratamiento específico. Se constituye la búsqueda de modalidades

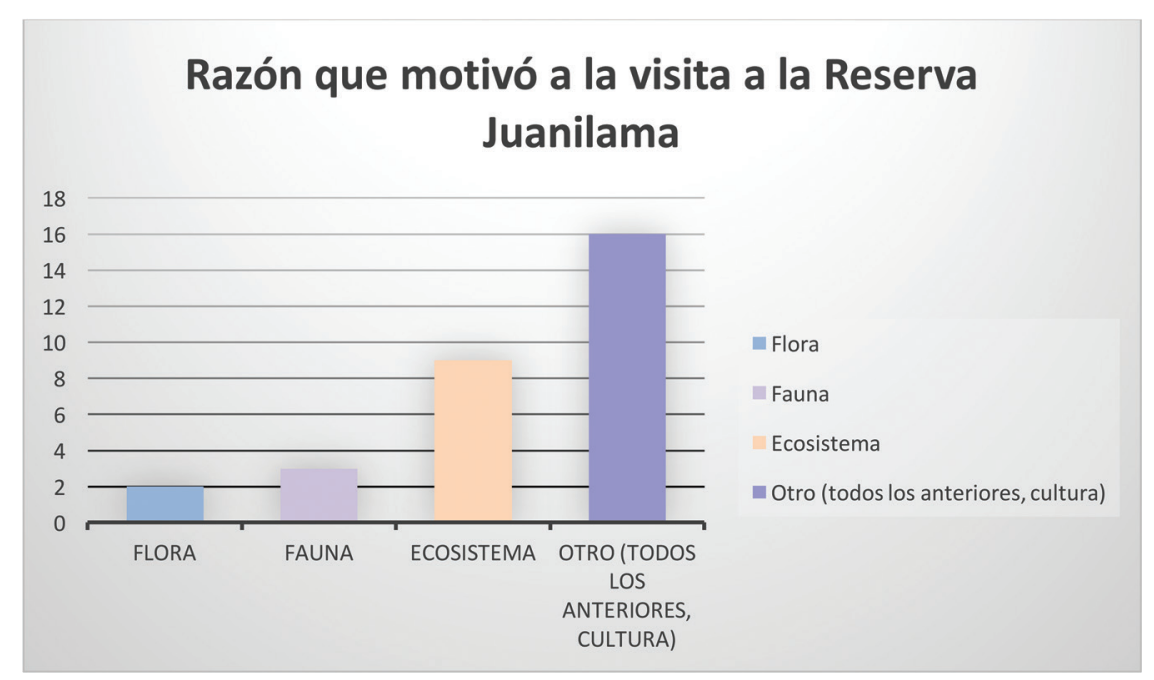

Figura 9. Distribución de acuerdo a principal atractivo que motivo la visita a la reserva Juanilama. Fuente: entrevista a los informantes, 2015. 
Planeamiento de organización territorial Reserva Juanilama.

\begin{tabular}{|c|c|c|c|}
\hline Zonas & Ubicación (por sendero) & $\begin{array}{c}\text { Distancia recorrida en metros } \\
\text { (sobre sendero) }\end{array}$ & $\begin{array}{c}\text { Coordenadas } \\
\text { (Inicio/Fin de la zona) }\end{array}$ \\
\hline \multirow[t]{2}{*}{ Zona de uso restringido } & \multirow[t]{2}{*}{ Sendero escalera de mono } & \multirow[t]{2}{*}{$439 m$} & N 10³9.680' - W 084³3.750' \\
\hline & & & N 10³9.740' - W 084²33.598' \\
\hline \multirow{2}{*}{$\begin{array}{l}\text { Zona de uso intensivo. } \\
\text { (mas propuesta) }\end{array}$} & \multirow[t]{2}{*}{ Sendero las Palmas } & \multirow[t]{2}{*}{740 m / (106 m propuesta) } & N 10³9.680' - W 084³3.750' \\
\hline & & & N 10॰39.695' - W 084³3.584' \\
\hline \multirow[t]{2}{*}{ Zona de uso extensivo. } & \multirow[t]{2}{*}{ Sendero las Palmas } & \multirow[t]{2}{*}{$539 m$} & N 10³9.787' - W 084³3.695' \\
\hline & & & N 10³9.789' - W 084³3.643' \\
\hline \multirow[t]{2}{*}{ Zona de uso especial. } & \multirow[t]{2}{*}{ Sendero escalera de mono } & \multirow[t]{2}{*}{$297 m$} & N 10³9.629' - W 084³3.885' \\
\hline & & & N 10³9.680' - W 084³3.750' \\
\hline
\end{tabular}

Fuente: Elaboración propia, 2016.

que permitan una acción más eficiente y una participación local más concreta en la resolución de conflictos de uso de los recursos naturales en ella. (Cuadro 3)

Para este estudio se definieron cuatro tipos diferentes de zonas, de acuerdo a las prioridades de manejo de la reserva Juanilama:

- Zona de uso restringido.

- Zona de uso público extensivo.

- Zona de uso público intensivo.

- Zona de uso especial.

Significados de los colores por categorías de zona

El propósito fue dividir el área de forma tal que cada componente pueda cumplir de manera positiva con los objetivos designados para la reserva.

Rojo. El color rojo se le asignará a la zona de uso restringido. Para este caso tendrá el significado de deténgase, restricción, condicionado.

La zona de uso restringido está constituido por sectores que presentan un alto grado de naturalidad. Aunque se haya percibido cierta intervención humana, sus valores naturales se mantienen en buen estado o en proceso de regeneración. Su creación y gestión permitiría el acceso a la investigación científica debidamente autorizada por la administración de la Reserva. Tanto como el manejo autorizado legalmente que encamina a la restauración de sus ecosistemas y especies de flora y fauna; así como la protección máxima de las especies con poblaciones amenazadas.

El acceso motorizado estará totalmente prohibido, así como el acceso continuo a la zona, este estará condicionado a las disposiciones anteriores. Además no se permitirá la modificación o alteración del sitio, ni la extracción de especies silvestres, salvo en casos muy especiales y bajo las estrictas medidas necesarias.

Naranja. El color naranja se le asignará a la zona de uso extensivo (sub-zona de uso público). Para esta categoría indicará que es zona de uso público bajo precaución y ciertos riesgos, al ser una zona más natural y de menor intervención. Los servicios y facilidades serán pocos y de bajo impacto, no se desarrollará infraestructura, salvo las mejoras mínimas en los senderos, esto como restricción para su uso en respuesta a cierta fragilidad de los recursos. El impacto humano será mínimo.

Amarillo. El color amarillo se le asignará a la zona de uso intensivo (sub-zona de uso público). En este caso significará que la zona es de acceso público; sin embargo, será bajo regulaciones: con excepciones podría desarrollarse uso público en forma esporádica y estricta. A pesar de ser una zona de gran concentración de visitantes deberá ser controlado mediante restricciones que posibiliten la sostenibilidad ambiental. Las 
construcciones e instalaciones deberán guardar el máximo respeto al entorno y se procurará su integración en el paisaje.

Verde. El color verde se asignará a la zona de uso especial. El cual tendrá el significado de descanso y seguridad, al ser la zona donde se concentrará la infraestructura y los servicios básicos.

Zona donde se ubicaran la mayor cantidad de instalaciones que se consideran necesarias para la gestión de la reserva.

\section{Enfoque de la zonificación}

El Proyecto atiende una doble condición del área que determinan sus prioridades de manejo: 1) el hecho de conservar los recursos naturales de la misma y 2) la necesidad de fortalecer el ordenamiento del turismo rural comunitario y ecológico.

La primera condición se orienta hacia el logro de un mejor manejo y conservación de las riquezas naturales del sitio: ecosistemas, especies de flora y fauna presentes, la naciente la clarita y la catarata la Leona.

La segunda condición se orienta al manejo y ordenamiento de las visitas a la reserva Juanilama con una demarcación de las zonas propuestas; sus características, objetivos e indicaciones y usos permisibles.

\section{Objetivo de las zonas de uso público}

El objetivo principal de la zona de uso público es facilitar el esparcimiento y las acciones turísticas y de educación ambiental, causando el menor impacto posible a los recursos naturales $\mathrm{y}$ al paisaje.

En consecuencia a la falta de planes de manejo en la reserva Juanilama, no se ha establecido una normativa estricta de las zonas de uso público que organice y controle el ingreso de visitantes, ni que estipule lo que se puede y lo que no puede hacerse dentro de cada segmento del área en estudio.
Criterios para la definición de las zonas de manejo en la Reserva

Buscando ordenar el manejo dentro del área protegida y dar lineamientos para la delimitación y manejo de la reserva, se analiza el territorio bajo criterios ambientales o ecológicos, socioculturales y de manejo.

Ambientales o ecológicos: al diferenciar progresivamente áreas muy naturales, alejadas y poco intervenidas o con poca accesibilidad, de otras con menor exigencia en cuanto a naturalidad, alejamiento y mayor accesibilidad. También sobre el estado de conservación: integridad ecológica y la importancia como ecosistema representativo.

Socioculturales: al diferenciar progresivamente condiciones de exclusividad y soledad hasta una creciente probabilidad de encontrar un número mayor de visitantes. Además determinar el valor histórico y la valoración local y/o regional.

Manejo: al diferenciar condiciones originales y con pocas señales de presencia humana de aquellas con creciente probabilidad de encontrar infraestructura, señalización y otras señales visibles de manejo y de ordenamiento.

\section{Definición de las zonas propuestas}

\section{Zona Restringida}

Definición: Esta zona será identificada por la denominación de color rojo. Zona conformada por ecosistemas frágiles que ameritan una protección, con la mínima interferencia humana a fin de conservar la integridad ecológica de los ecosistemas. No se permitirá ningún tipo de actividad, salvo aquellas de investigación previamente autorizadas por la administración de la reserva. (Fig. 10)

Objetivo de manejo: Preservar el medio ambiente natural en condiciones naturales, permitiéndose solamente el uso científico 


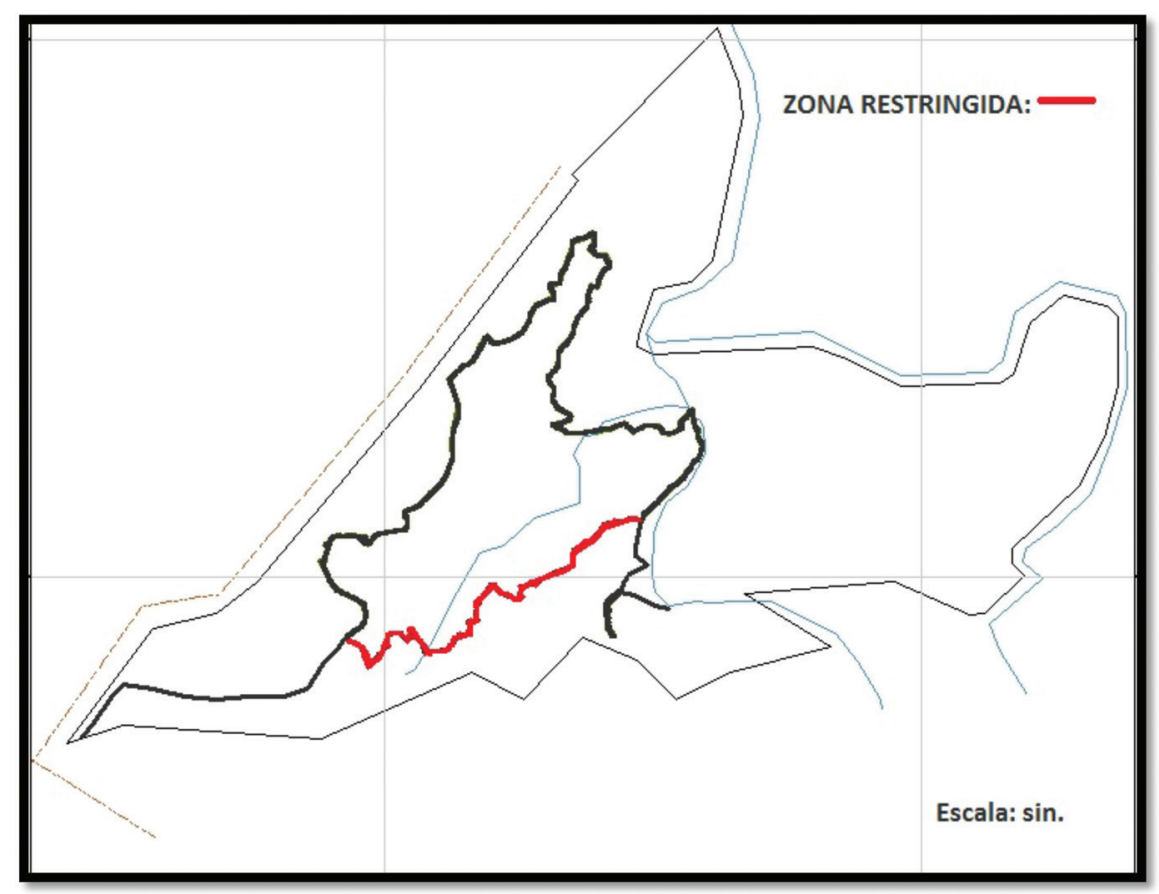

Figura 10. Mapa Propuesta Zona Restringida en Reserva Juanilama. Fuente: elaboración propia, 2016.

y las funciones de protección y administración estrictamente necesarias.

\section{Características:}

- Alto grado de naturalidad.

- Hábitats y nichos ecológicos de naturaleza frágil y de gran interés científico.

- Presencia de especies de flora y fauna o manifestaciones naturales que requieren de protección especial por su alto valor científico y de conservación.

- Condiciones de acceso y recorrido con un grado de dificultad alto.

- Valoración local por la importancia de los ciclos naturales que se desarrollan.

\section{Normas para su uso:}

- Se permite únicamente el acceso público especializado y esporádico.

- No se permite ningún tipo de construcción o alteración del ambiente.
- Se permite el acceso solamente para el uso científico o investigativo, previamente autorizado por la administración de la reserva.

\section{Zona de Uso Público Extensiva}

Definición: Esta zona será identificada por la denominación de color naranja. Zona conformada por ambientes naturales de relevancia y que su constitución, relativamente resistente, pueda tolerar un moderado uso público dedicado a la realización de estudios científicos, apreciación del paisaje y la naturalidad del lugar. (Fig. 11)

Objetivo de manejo: Preservar aquellas áreas relevantes de la reserva de perturbaciones y modificaciones causadas por el ser humano; así como brindar la oportunidad de recreación extensiva al aire libre, en un ambiente natural de gran belleza escénica.

\section{Características:}

- Formaciones naturales o manifestaciones poco comunes de la naturaleza. 


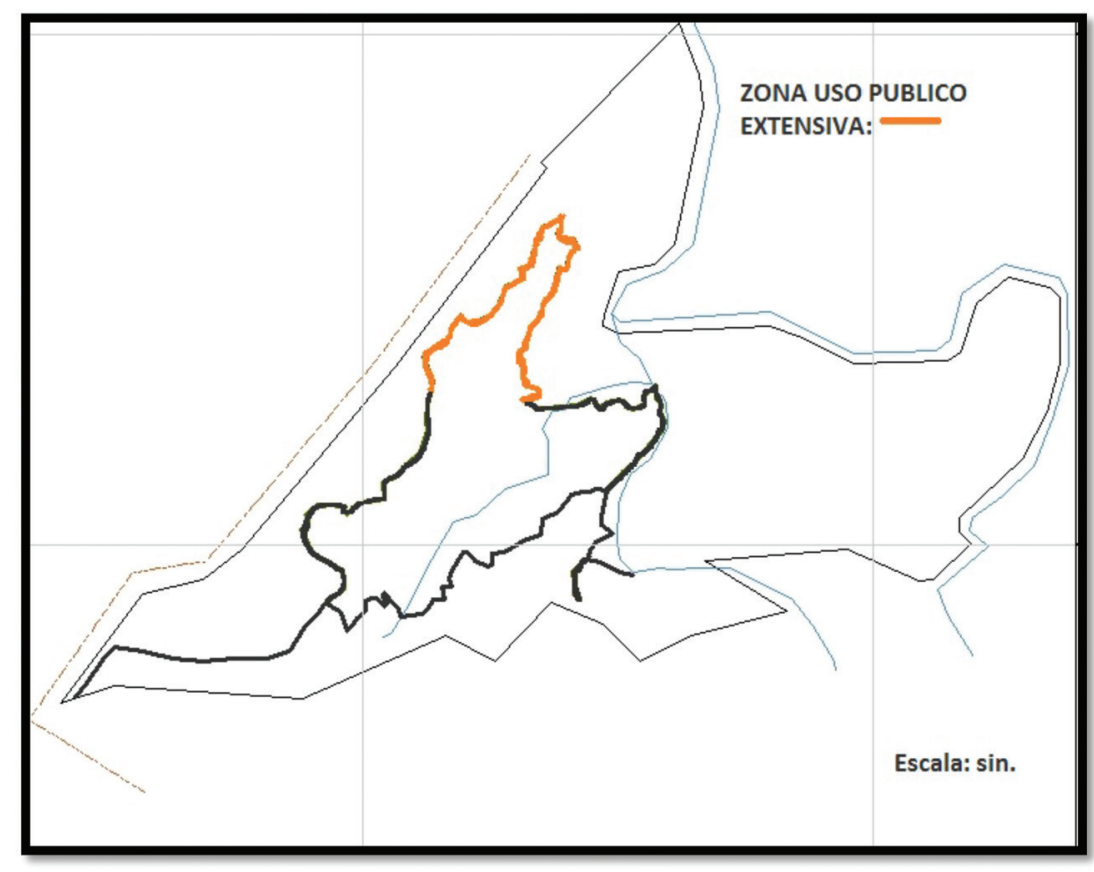

Figura 11. Mapa Propuesta Zona Uso Público Extensiva en Reserva Juanilama. Fuente: elaboración propia 2016.

- Ambientes de gran valor biológico y/o escénico.

- Entorno con escaza o ninguna alteración antropogénica

- Bosques en estado de sucesión y excelente estado de conservación.

- Fragilidad física y/o biológica.

\section{Normas para su uso:}

- Se permite un uso público muy limitado, restringido solamente a caminatas y campamentos primitivos.

- La intensidad de su uso está limitado al goce del escenario natural y la observación de sus atractivos especiales, cuidando en todo momento de preservar su calidad y mantener su integridad.

- No se permiten construcciones, salvo un mínimo de senderos, para efectos de recreación o administrativos.

- No se permite el uso de vehículos motorizados.

- Se permite una señalización mínima.
- Se permite la investigación científica y recreación esporádica.

\section{Zona de Uso Público Intensiva}

Definición: Esta zona será identificada por la denominación de color amarillo. Zona conformada por aquellos sectores de la reserva que por sus características son aptos para la recreación al aire libre, aceptando la construcción de infraestructura mínima y concentraciones de visitantes en la forma y modalidades que establezca la reserva Juanilama. (Fig. 12)

Objetivos de manejo: Facilitar el desarrollo de la recreación intensiva y la educación ambiental de manera que el visitante armonice y se integre al ambiente natural de la reserva, provocando el menor impacto posible sobre ésta y las bellezas naturales y escénicas

Implementar como complemento la creación de un sendero alternativo que conecte directamente al atractivo turístico principal y que a la vez limite el acceso a la zona restringida propuesta (ruta principal de acceso al destino turístico en la actualidad). 


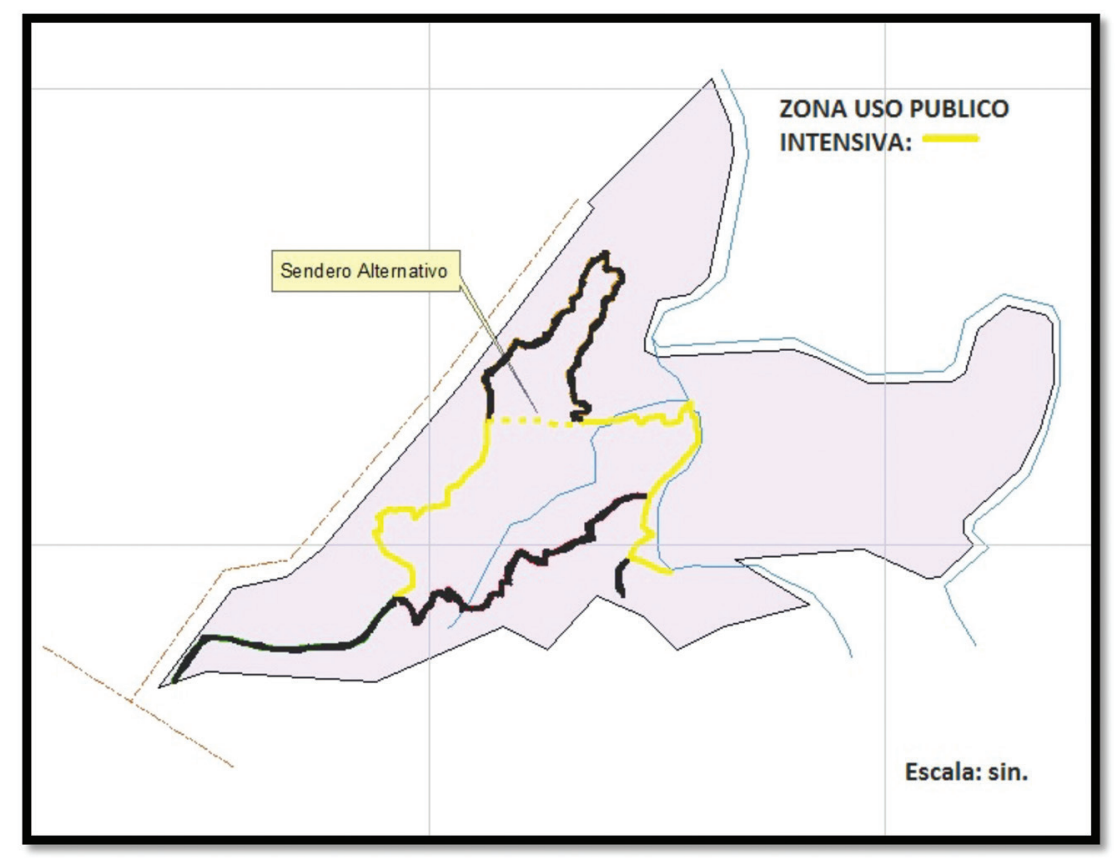

Figura 12. Mapa Propuesta Zona Uso Público Intensiva en Reserva Juanilama. Fuente: elaboración propia, 2016.

\section{Características:}

- La ubicación de esta área, debe estar conectada con el área de ingreso principal.

- Entorno natural con buen estado de conservación.

- Área natural en la cual los recursos se presten para actividades recreativas relativamente densas y su topografía se preste para desarrollar infraestructura de apoyo, vías de acceso, etc.

- Presencia de atractivos naturales turísticos como por ejemplo la catarata.

\section{Normas para su uso:}

- Se permite el acceso público regular, siempre y cuando este no afecte los objetivos de conservación de la reserva.

- No se permite ningún uso público fuera de los senderos establecidos.

- Se permite la señalización moderada del área.

- No se permite el uso de vehículos motorizados.

\section{Zona de Uso Especial}

Definición: Esta zona será identificada por la denominación de color verde. Zona modificada específicamente para el uso público dentro de un paisaje natural o semi-natural. También son parte de esta categoría los sitios con infraestructura edificada y adaptada, para la enseñanza ambiental y satisfacer las necesidades básicas como los servicios sanitarios. Así como también infraestructura o sitios adaptados para la venta de artículos de artesanía. (Fig. 13)

Objetivo de manejo: Otorgar la oportunidad de visitar sitios y centros de interpretación especialmente preparados y acomodados para la visita de turistas, pobladores y estudiantes con interés en aspectos naturales, culturales, históricos o científicos y de conservación.

\section{Características:}

- Sitios modificados especialmente para el uso público dentro de un paisaje natural o semi natural. 


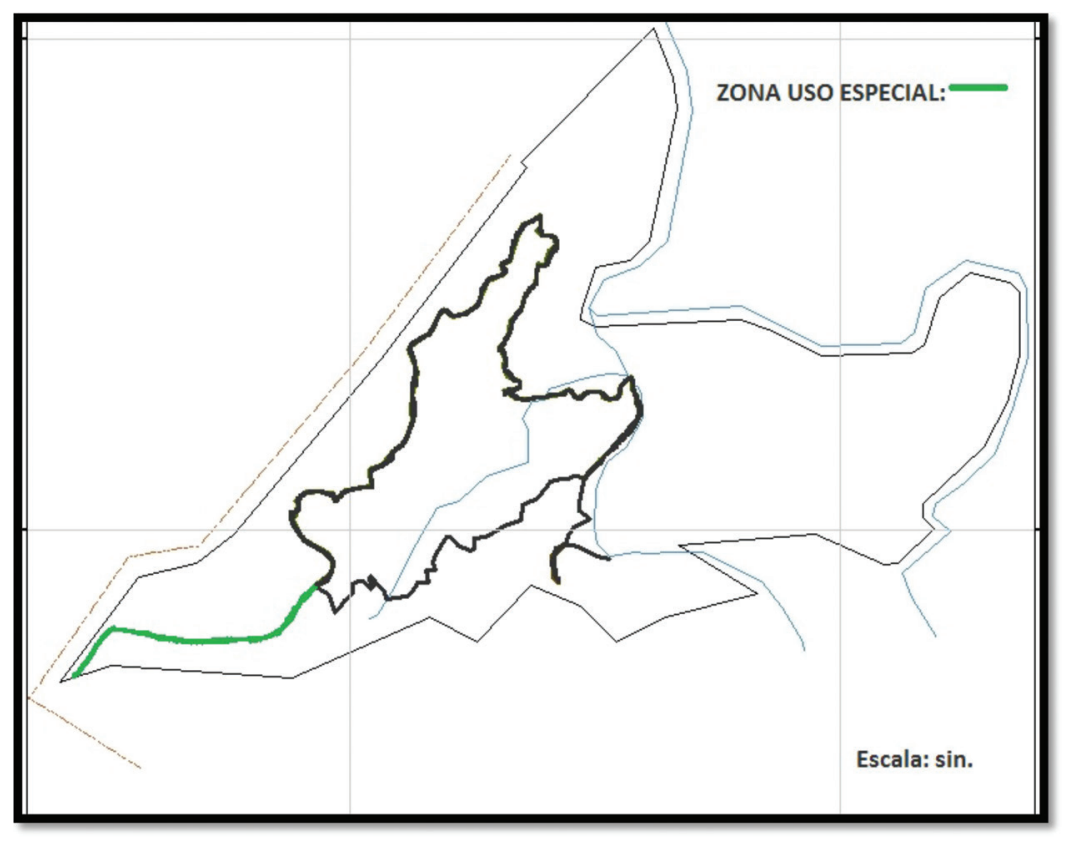

Figura 13. Mapa Propuesta Zona Uso Especial en Reserva Juanilama. Fuente: elaboración propia, 2016.

- Infraestructura adaptaba para la enseñanza ambiental.

- Alta capacidad de soporte, facilidades y servicios guardando siempre las consideraciones ambientales.

\section{Normas para su uso:}

- Se permite la conducción con grupos de visitas guiados.

- El ingreso de visitantes a los sitios cerrados o destinados a la educación ambiental debe ser controlado.

- Los sitios deben contar con la presencia constante de personal y de personal de vigilancia.

- El personal de vigilancia debe instruir a los visitantes acerca de la conducta que estos deben tener en el sitio, en lo referente a los desechos producidos, las actividades no permitidas, la perturbación a otros visitantes o a las especies presentes.
Identificación de factores y características que influyen en cada sitio de visita

Se determina por medio del levantamiento con GPS que la longitud total de los senderos dentro de la reserva en la actualidad es de 2.33 kilómetros, donde la mayoría presentan pendientes e inclinaciones pronunciadas. Los senderos reflejan un grado de fragilidad al presentar una topografía irregular y con mucha pendiente, lo que los constituye como suelos de difícil acceso y control ante eventos naturales. (Fig. 14)

Cabe destacar que hubo una reducción de la longitud de los senderos, ya que hasta 2014 la distancia total era 2.60 kilómetros; sin embargo, por decisiones administrativas se cerró en 2015 un segmento de casi 30 metros lineales, con el fin de permitir su restauración, ya que en la actualidad se encuentra obstruido y representa un peligro para los visitantes en cuanto a su seguridad.

La reserva posee tres senderos a saber: el Escalera de Mono, la Ceiba (sendero cerrado) y sendero Las Palmas. 


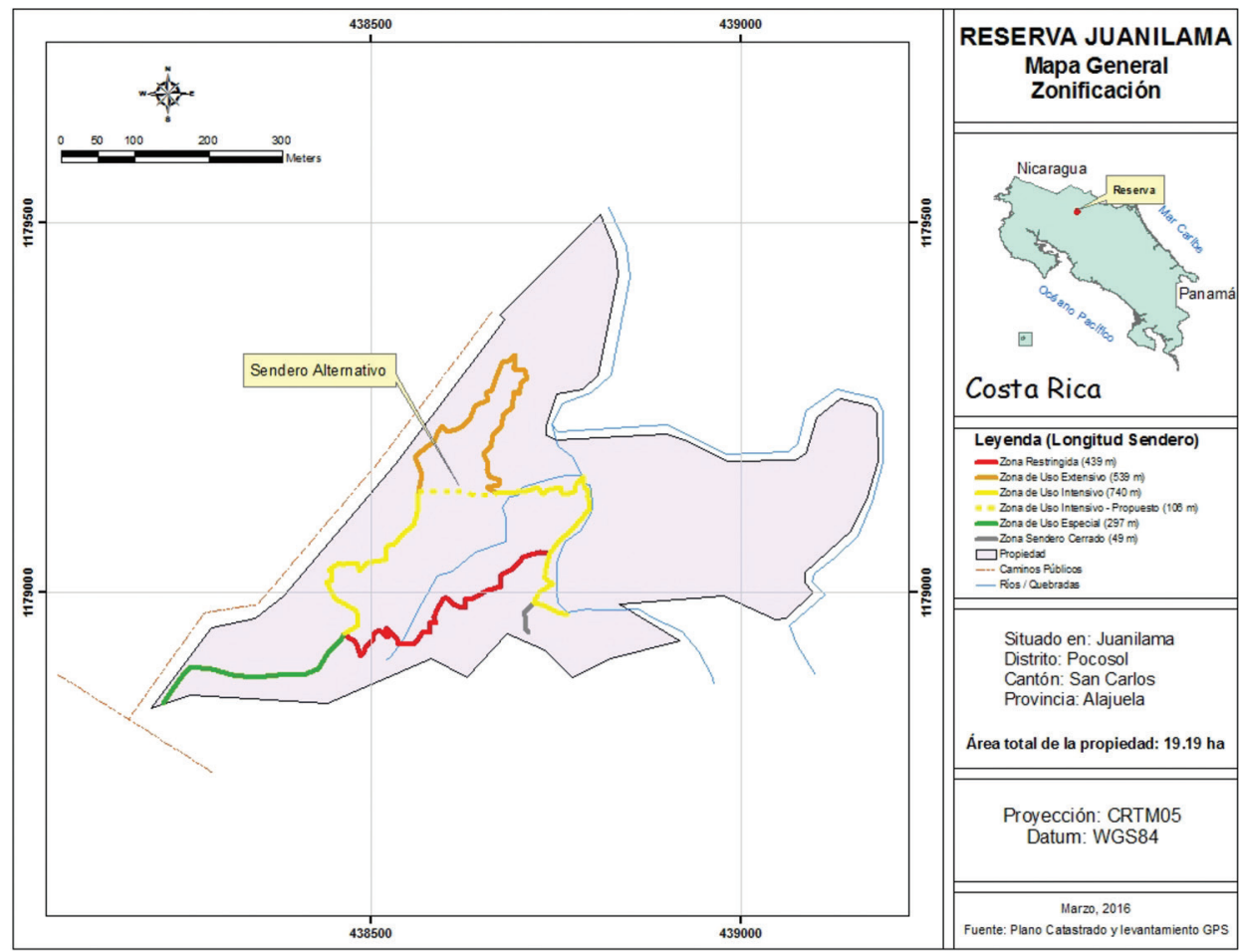

Figura 14. Mapa Propuesta de Zonificación y sendero alternativo para reserva Juanilama. Fuente: Ulloa, 2016.

\section{El sendero Escalera de Mono}

Es de tipo lineal, un segmento del sendero es de fácil acceso; sin embargo al avanzar el recorrido presenta un grado de dificultad alto y se vuelve de difícil acceso. Este sendero atraviesa a la quebrada Clarita.

\section{El sendero Las Palmas}

Se presenta como un sendero natural, por lo tanto no tiene facilidades para el paso de los visitantes y presenta gran cantidad de segmentos con alguna dificultad. Este recorre parte de la montaña por lo tanto presenta una alta inclinación y un grado de dificultad alto, que lo hace accesible solo para personas con una buena condición física. Este sendero es de tipo lineal y lleva hacia los márgenes del río Pocosol.

El sendero Escalera de Mono y el Sendero las Palmas se comunican entre sí (Las Palmas recorre la reserva al norte y el Escalera de Mono al sur) formando una red de sendero circular, ambos llevan el recorrido hacia el sendero la Ceiba y hacia la catarata La Leona, la cual es el principal atractivo de la reserva como puede apreciarse en la Figura 15.

El paisaje de los senderos está compuesto por áreas de bosques intermedio primario. Según los entrevistados, y las propias observaciones; en lo que respecta a los elementos ecológicos de importancia y especies vulnerables presentes, se logra determinar una parte del sendero Escalera de Mono en donde se concentran las especies más frágiles y los ecosistemas de mayor importancia ecológica para el sitio en investigación, dentro de este segmento se encuentra la única naciente de la reserva Juanilama, de la cual surge la quebrada Clarita, factor fundamental para que se desarrolle el ecosistema idóneo para especies como la ranita roja (Oopaga pumilio) y la ranita venenosa verde y negro (Dendrobates auratus), especies con poblaciones amenazadas o reducidas que requieren ser protegidas. 


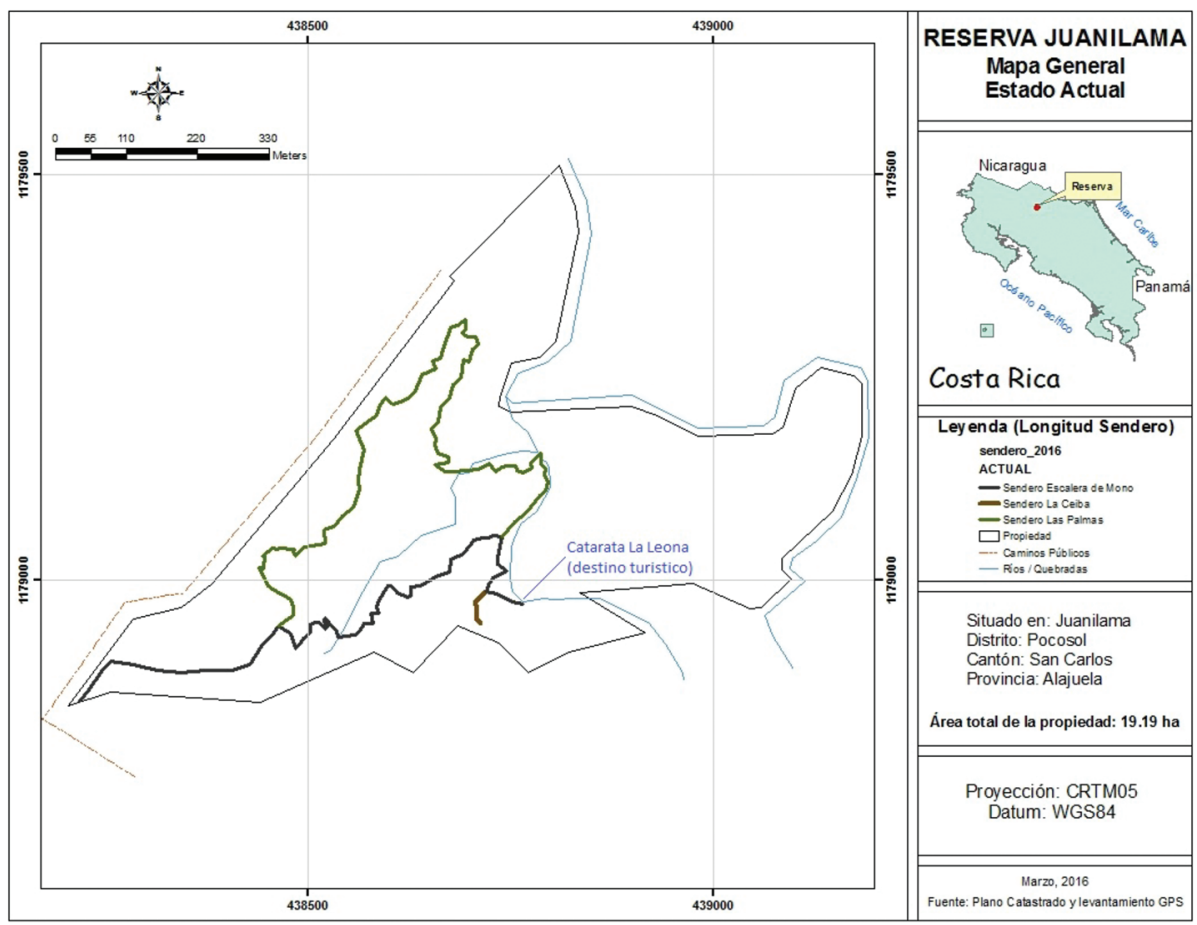

Figura 15. Senderos de la Reserva Juanilama. Fuente: Ulloa, 2016.

Propuesta de manejo de visitantes

\section{Prioridades de Manejo de la Reserva Juanilama en concordancia a la atención de visitantes}

Se consultó a personal encargado de la administración de la reserva sobre las prioridades de manejo, en efecto el señor Salazar (2015), indicó, en orden de importancia:

\section{a. Establecer una zona de uso restringido para} la investigación, resaltando la importancia de un sitio restringido, destinado a futuras investigaciones de las diversas universidades que visitan la reserva.

En ese sitio habría interés por proteger especies de flora y fauna vulnerables; así como conservar muestras representativas de ecosistemas, ya que la reserva posee recursos paisajísticos para el disfrute de los visitantes, que requieren ser protegidos por su valor intrínseco. b. Mejoramiento y mantenimiento de la red de senderos y su infraestructura.

Es importante mencionar que la prioridad es destinar los senderos únicamente a personas con las capacidades físicas necesarias para recorrerlos. A pesar de esto se analiza la opción de adoptar una propuesta que permita ordenar, controlar y manejar de manera adecuada a los actuales y potenciales visitantes de la reserva Juanilama, con el fin de mejorar la calidad de la experiencia en el momento del ingreso a la reserva y además la de los servicios turísticos ofrecidos hasta el momento como lo son, la estadía en casas de vecinos a la reserva, servicios básicos, alimentación, tours y caminatas, talleres de artesanía, entre otros.

c. Establecer un espacio dirigido a la educación ambiental, donde se puedan realizar charlas, talleres, y actividades afines y que a la vez se pueda equipar de artículos, afiches, posters, guías botánicas, etc. acerca de 
información representativa, interesante y de importancia dentro de la reserva sobre sus recursos biológicos y ecológicos.

Además como complemento, el personal encargado de la administración de la reserva tiene la idea de fomentar un proyecto para la creación de un espacio de exposición y venta de productos y artesanías tradicionales, con el fin de mostrar las costumbres de la zona a los visitantes.

Objetivo de uso. Establecer un instrumento de ordenamiento y manejo de visitantes por medio de directrices, políticas y una propuesta de zonificación que fomente la protección de los recursos naturales y prevenga el deterioro ambiental en la Reserva Juanilama.

\section{Políticas y directrices para visitantes}

- Exigir que el visitante reciba instrucciones antes de entrar.

- Las actividades que realizan los visitantes en esta zona deben ser reguladas y ordenadas por un reglamento de uso público.

- Se permite la visitación pública según horarios establecidos por la administración del área.

- Las actividades que realicen los visitantes deben estar acordes con los objetivos de conservación de la reserva.

- Mantenimiento periódico de la infraestructura, instalaciones y equipamiento turístico del área protegida.

- Delimitación clara de todos los senderos del área protegida.

- Carteles de señalización de senderos, miradores, servicios públicos y carteles de recomendaciones de comportamiento de los visitantes dentro del área protegida.

- La administración de la reserva podrá cerrar temporal o indefinidamente, los sitios de uso público por razones de seguridad u otros adecuadamente justificados.

- Todas las actividades recreativas y/o turísticas que realicen los visitantes deben ser coherentes con los objetivos de conservación de la reserva.
- Se promoverá la investigación básica aplicada sobre la flora, fauna y restauración de bosques degradados.

- Informar a los visitantes de las condiciones que puedan encontrar (recursos susceptibles, etc).

- Contar con un sitio de información con equipo y materiales informativos y así obtener una mayor comodidad del visitante a la hora de ingresar la reserva. Estos podrán servir a las personas de diferentes maneras:

- A manera de bienvenida, donde permita que los visitantes se sientan esperados, exhibiendo un rotulo de bienvenida.

- Orientar al visitante, que permita que los visitantes conozcan el tipo de cosas que ellos pueden ver y hacer en el área. Contar con mapas, entre ellos uno grande que les indique a los visitantes donde están, localización de los detalles y puntos de interés, folletos y otra información no solo de la reserva si no de las zonas cercanas al área.

- Sensibilizar a los visitantes sobre el valor del área, brindando información donde explique las razones de la existencia del sitio e indicando como deben conducirse los visitantes a fin de evitar un impacto negativo en los sitios del área.

- Atender las necesidades del visitante, localizaciones de los servicios sanitarios, agua potable, áreas para comer, entre otras.

- Contar con folletos, fotografías, especímenes de objetos o detalles de importancia natural y cultural del lugar, además ser perceptivo a los intereses de los visitantes y brindar información adicional.

Contar con diferentes tipos de rótulos en el área, de orientación, de facilidades y servicios, de advertencia, educativos, etc, que permitan al visitante una mejor ordenación y satisfacción. Por lo que será importante el uso de diseños y colores adecuados según el tipo de información que se requiera transmitir. 


\section{Discusión}

Se vive en un mundo donde la diversidad ecológica va en disminución; se extraen recursos de la naturaleza y se modifican paisajes a tasas que no pueden ser sostenidas, dando lugar a índices de extinción acelerados, a la degradación y pérdida de ecosistemas y a la ruptura de los sistemas naturales en los cuales se insertan nuestras culturas (Trombulak et al, 2004). Por ello en base a los resultados obtenidos se puede observar la adecuada iniciativa de la reserva Juanilama en optar entre sus prioridades de manejo con vistas al manejo de visitantes, la idea de crear una zona exclusiva a la protección de ecosistemas y especies más vulnerables, con el fin de colaborar en la conservación de los recursos biológicos y científicos de la zona y a la vez educar a la población referente a la problemática mundial en cuanto a la disminución de la diversidad ecológica.

Como se logra identificar en los datos obtenidos, la reserva Juanilama hasta la fecha no cuenta con un plan general de manejo, causando inconvenientes de gestión, tanto de los recursos naturales presentes en el interior de la reserva como el de manejo de visitantes que ingresan a la reserva. Ante esto un gran aporte a la administración de la reserva es presentar una propuesta de zonificación que les permita tener una base para empezar en el diseño del plan general de manejo; siendo este instrumento un aporte de gran magnitud para este tipo de proyectos.

Es por esta situación que se toma en cuenta la falta de un instrumento que permita controlar la situación y garantizar los principios de conservación de la reserva, este instrumento es la zonificación y más específicamente la creación de una zona restringida que sea definida y congruente a sus características y en la que se cumpla con lo establecido en ella.

En la aplicación del diseño de una propuesta de manejo de visitantes se opta por seleccionar una metodología poco utilizada en Costa Rica (SIMAVIS), su definición, aspectos y características involucran un método más ordenado y adaptable a diferentes tipos de Áreas Silvestres Protegidas para el manejo de visitas, se analiza que en este sistema al contrario de otros métodos actualmente utilizados como por ejemplo el de Capacidad de Carga Turística (CCT) para determinar el número de visitantes que puede soportar un área, se utilizan otras variables que pueden ser aplicables a ciertas Áreas Protegidas del país y sobretodo que podrían resultar de mayor facilidad de aplicar por los administradores de las mismas.

Por su parte SIMAVIS se enfoca en principios como: 1. Los impactos de los visitantes no son proporcionales a su número, sino principalmente a su comportamiento, 2. Se adapta a las condiciones de cada área 3. En lugar de determinar una capacidad de carga, se determina tomando en cuenta aspectos naturales y físicogeográficos, como también sociales, culturales y de intervención humana, 4. La metodología se enfoca fuertemente en la calidad de la experiencia de los visitantes, por tanto valora mucho el análisis y las percepciones subjetivas y empíricas de los actores sociales (ECOLAP, 2010).

Dado esto se logra determinar que la metodología SIMAVIS podría colaborar con la falta de planificación que sufren muchas áreas protegidas en cuanto al manejo de visitantes. Aunque no se toma en cuenta la capacidad de carga turística, se toma en cuenta aspectos naturales, sociales y culturales y físicos-geográficos. Además no se enfoca en la cantidad de visitantes que ingresen, si no en su comportamiento e interacción con el ambiente.

Otro aspecto a considerar dentro de las prioridades de manejo de la reserva en cuanto al manejo de visitantes, es el estado de los senderos y zonas donde se hará presencia de visitantes. Aunque para la reserva Juanilama, su prioridad es recibir a personas con las condiciones físicas necesarias para ingresar al interior de la reserva, debido a las características irregulares del área en cuanto a suelos, morfología y peligros secundarios como la presencia de animales silvestres que pueden significar un grado de peligro para las personas que ingresen, es indispensable establecer un marco regulatorio, y con estándares mínimos de seguridad para los visitantes. Al respecto Jiménez, Gómez, Font y Chamberlain (s.f) indican que debe existir información de 
prevención y seguridad para los visitantes en Áreas Protegidas.

Para el caso de la reserva Juanilama se destacan y adaptan de esos autores:

- El usuario deberá contar con información que le permita conocer anticipadamente las características y condiciones específicas que tiene el camino que está recorriendo y el lugar en general. Aspectos relevantes como la presencia de gradas, caminos inestables, resbalosos, con precipicios a la orilla del camino, entre otros.

- Informar y señalizar cuáles son los senderos accesibles para la población con alguna discapacidad. La señalización de prevención y seguridad debe contener información accesible que cumpla con las características y normas establecidas.

- Por otro lado Morea (2014), indica que en la actualidad la planificación del Uso Público en un área protegida tiene como objetivos:

- Diseñar una estrategia que permita lograr el desarrollo sustentable del turismo en un espacio de valor para la conservación de la biodiversidad, con los correspondientes efectos positivos y mitigación de los negativos.

- Desarrollar proyectos turísticos y otras alternativas productivas de manera compatible con los objetivos de conservación.

- Desarrollar proyectos turísticos cuyos beneficiarios sean prioritariamente las comunidades locales.

- Promover en los visitantes, una actitud de interés y cuidado por la naturaleza y las culturas locales.

- Obtener amplios consensos en la detección y el diseño del uso público, mediante la aplicación de metodologías participativas que lleven al logro del compromiso social con la conservación en el área.

Ante esto se puede relacionar lo anterior y percibir que en el proyecto de ecoturismo desarrollado en la comunidad de Juanilama y en el que se involucra directamente a la reserva en la que se realizó el estudio, se ve reflejado el interés de la administración del sitio en diseñar una propuesta para el manejo de visitantes y de las zonas de uso público como estrategia para el desarrollo de la actividad turística, que les permita realizar nuevos e innovadores proyectos de ecoturismo e implementar medidas de conservación amenas, a partir de los resultados de esta investigación.

Cabe destacar que se pretende como alcance que los mayores beneficiados sean los actores locales de la comunidad, que a través de los años se han preocupado por la conservación de los recursos naturales y culturales de la zona y a la vez lograr un aprovechamiento económico de manera sostenible con el ambiente, creando así una actitud consiente entre las relaciones del destino, la comunidad, la reserva, la población local y los visitantes.

Cabe reiterar que la reserva Juanilama tiene como prioridad la conservación de los recursos naturales, siendo esta reserva un área protegida de gran importancia y con segmentos del sitio muy vulnerables, por lo que optaron por la implementación del ecoturismo en la comunidad, con el fin de crear nuevas oportunidades para los vecinos de la zona y para las localidades cercanas. Sin embargo, no se ha tomado en cuenta el hecho de que la visitación de turistas pueda aumentar considerablemente y no podrían resolver el cómo controlar la situación de manera adecuada ante la falta de instrumentos de manejo.

Como se presenta en los resultados, este proyecto del ecoturismo en la zona, actualmente ha ido en aumento. Por el hecho de que la visitación turística este aumentando en los últimos años, es de gran responsabilidad para Manejadores de Recursos Naturales y para la administración de la reserva y de reservas naturales en general, conocer hasta qué punto el aumento de la visitación de turistas a un área protegida es sostenible con los objetivos de manejo de la reserva. De ahí la importancia de la elaboración de una propuesta de zonificación como un aporte de gran ayuda para el manejo de visitantes y su ordenamiento que permita empezar con la planeación de la 
elaboración de un plan de manejo para la reserva Juanilama. Quizá la parte más importante de un plan de manejo sea el sistema de zonificación que se establezca, puesto que estas zonas determinarán el tipo de manejo que áreas específicas recibirán, lo cual a la vez permitirá definir acciones específicas de manejo (Moore, 1985).

La propuesta de la creación de un sendero alternativo es una forma de lograr que se desvíe el tránsito de visitantes de las zonas más frágiles e irregulares, hacia otra que tenga mayores facilidades de acceso y que a la vez sea accesible a más perfiles de visitantes, es un imperativo para ir paulatinamente disminuyendo el impacto que puede causar la visitación en los recursos naturales más vulnerables de la reserva Juanilama.

\section{Conclusiones y recomendaciones}

Ante el aumento de los últimos años en la visitación de turista extranjero y nacional a la reserva Juanilama y con el fin de mantener los objetivos de conservación, surge la iniciativa de la administración por determinar las prioridades de manejo de la reserva en concordancia al manejo de visitantes.

La Reserva Juanilama no cuenta con planes de manejo de ningún tipo, la Propuesta de Manejo de Visitantes en el que se incluye una propuesta de Zonificación interna, como un instrumento de ordenamiento permite una mejor organización, dirección y control de las zonas de uso público.

Se logra identificar la importancia científica y biológica de la reserva Juanilama, debido a la presencia de especies vulnerables y amenazadas, y la presencia de una naciente de importancia para la comunidad.

La actividad recreativa se ha convertido en una necesidad social, ante el aumento del turismo las áreas silvestres protegidas tanto gubernamentales como no gubernamentales o privadas, deben prepararse con un planeamiento del cómo hacerle frente a ese tipo de circunstancias, por medio de una mayor participación de las comunidades en el ámbito del turismo sostenible.

Establecer y delimitar mediante la propuesta de Zonificación, un área en el interior de la reserva dedicada a la investigación científica, como herramienta para el conocimiento y futuras investigaciones en el ámbito de los recursos naturales y científicos es una forma de colaborar en aspectos técnicos y operativos de empezar con las prioridades establecidas al implementar un plan de manejo general para organizar y ordenar su funcionamiento de manera tal que permitan disminuir o controlar el impacto de las visitas a las zonas de uso público y cumplir sus objetivos jerárquicamente superiores.

\section{Fuentes de información}

Amend, T y Amend, S. (s.f). La zonificación: elemento clave de los planes de manejo. Recuperada de http://www.zonasdeamortiguamiento.org/descargas/ ZONIERUNG_S.pdf

Artavia (2004) citado por Bermúdez, F (2007). Plan de Uso Público del Parque Nacional Isla del Coco. San José, Costa Rica: PNUD-GEF y FFEM.

Bermúdez, F. (2007). Plan de Uso Público del Parque Nacional Isla del Coco. San José, Costa Rica: PNUDGEF y FFEM.

Bermúdez, F., y Conejo, R. (2008). Plan General de Manejo Parque Nacional Volcán Irazú. San José, Costa Rica: ACCVC.

Calvo Bolaños, Evier. (2013). Com.pers. Ex Guía local de Reserva Juanilama, Pocosol, San Carlos, Alajuela. Entrevista realizada el 08 de noviembre de 2013.

ECOLAP. (2010). Sistema de Manejo de Visitantes (SIMAVIS). Recuperada de https://sites.google.com/ site/proyectosimavis/

Gunter, R. (2011). Microzonificación Turística. Recuperada de https://docs.google.com/viewer?a=v\&pid=sites\&srcid=ZGVmYXVsdGRvbWFpbnxlY29sYXBza W1hdmlzfGd4OmRlZjRjYTRmYjEyMzEyMg

Hernández, J., y Gómez-Limón, J. (2005). Conceptos de uso público en los espacios naturales protegidos. Recuperada de http://www.redeuroparc.org/documentos_anexos/Publicaciones/ligadas_a_plan_de_accion/ manual_1.pdf

Instituto Geográfico Nacional, MOPT. (s.f). Hoja Topográfica Monterrey 061 escala 1:50000. 
Recuperada de http://www.mapasdecostarica.info/ completas/hojas/061_monterrey.htm

Jiménez, R., Gómez, K., Font, M. J., y Chamberlain, C. (s.f). Guía de prevención y seguridad en áreas protegidas para personas con discapacidad. Recuperada de http://www.accessibletourism.org/resources/15_guia_ prevencion_areas_protegidas_es.doc

Molina Jiménez, Sandra. (2016). Com.pers. Miembro Asociación Agroecológica Juanilama. Pocosol, San Carlos, Alajuela. Entrevista telefónica realizada el 16 de Febrero de 2016.

Moore, A. W. (1985). Manual de operaciones para sistemas de áreas protegidas. Roma, Italia: FAO.

Morea, J. P. (2014). Situación actual de la gestión de las áreas protegidas de la Argentina. Problemáticas actuales y tendencias futuras. Revista Universitaria de Geografía. Recuperada de http://www.scielo.org.ar/scielo.php?script=sci_arttext\&pid $=\mathrm{S} 1852-42652014000100003$
Ruiz, A. (2015). Principios de Infraestructura básica para Áreas Silvestres. Versión Preliminar. San José, Costa Rica: EUNED.

Salazar Guerrero, Olguín. (2015). Com.pers. Secretario Asociación Agroecológica Juanilama y encargado del control de visitas Reserva Juanilama. Pocosol, San Carlos, Alajuela. Entrevista realizada 28 agosto 2015.

Trombulak, S. C., et al. (2004). Pautas Recomendadas para la Comprensión e Instrucción de la Conservación. Recuperada de https://conbio.org/images/content_ prof_dev/conservation_literacy_espanol1.pdf

Ulloa, G. (2013). Com.pers. Mapa de ubicación de Reserva Juanilama. Gerente Forestal. Ethical Forestry: Santa Rosa de Pocosol.

Ulloa, G. (2016). Com.pers. Mapa estado actual de senderos en Reserva Juanilama. Gerente Forestal. Ethical Forestry: Santa Rosa de Pocosol.

Ulloa, G. (2016). Com.pers. Mapa Propuesta de Zonificación y sendero alternativo para reserva Juanilama. Gerente Forestal. Ethical Forestry: Santa Rosa de Pocosol. 
